\title{
Article \\ Policy Effect on Clean Coal-Fired Power Development in China
}

\author{
Jianyun Zhang ${ }^{1}$, Xinxin $\mathrm{Li}^{2}$ and Lingying Pan ${ }^{2, *}$ \\ 1 China Energy Technology and Economics Research Institute, Beijing 102211, China; \\ 20024504@chnenergy.com.cn \\ 2 Business School, University of Shanghai for Science and Technology, Shanghai 200093, China; \\ xinxinhappy0812@163.com \\ * Correspondence: panly@usst.edu.cn; Tel.: +86-021-65710428
}

Citation: Zhang, J.; Li, X.; Pan, L. Policy Effect on Clean Coal-Fired Power Development in China. Energies 2022, 15, 897. https:// doi.org/10.3390/en15030897

Academic Editors: Feng Wang and T M Indra Mahlia

Received: 8 December 2021

Accepted: 6 January 2022

Published: 26 January 2022

Publisher's Note: MDPI stays neutral with regard to jurisdictional claims in published maps and institutional affiliations.

Copyright: (c) 2022 by the authors. Licensee MDPI, Basel, Switzerland. This article is an open access article distributed under the terms and conditions of the Creative Commons Attribution (CC BY) license (https:// creativecommons.org/licenses/by/ $4.0 /)$.

\begin{abstract}
The coal power policy has been influencing the development of China's coal power industry from the aspects of quantity control, technological progress, and market-oriented reform. Meanwhile, the strategic coal power policy of the mid- and long-term future is yet to be well-designed under the carbon peak and neutrality targets. Therefore, it is necessary to have a comprehensive overview of the coal power policy during the past and give targeted prospects for policy-makers. This paper discusses the policy effect on the development and technological progress of the coal power industry by giving an overview of the policy and reform processes of the coal power industry in China in the past 20 years. The results indicate that China's coal power policy has promoted the progress of coal power generation technology, optimized the coal power structure, accelerated the diversified investment in the power industry, and alleviated the overcapacity problem of coal power generation. After discussion, we conclude that: (1) It is necessary to gradually reduce the average generation hours of coal-fired power units while retaining high-quality coal-fired power units. (2) The renewable energy enterprises that adopt the support services of coal power enterprises should provide reasonable capacity compensation costs to create favorable conditions and achieve sustainable development for China's coal power industry. (3) To deploy coal power units combined with large-scale renewable energy in the western and northern regions will achieve efficient energy utilization. (4) Different strategies should be adopted for different coal power units, and the peak regulation potential of coal power units with low-capacity parameters should be explored.
\end{abstract}

Keywords: clean coal-fired power; policy driver; policy effects; future challenges

\section{Introduction}

In China, the power industry with rapid development has underpinned the nation's continuous and robust economic growth for decades [1]. Given China's resource endowment, featuring rich-in-coal, as well as the cost competitiveness, coal-fired power has been serving as a pillar of the domestic electricity generation fleet, accounting for $61 \%$ of the overall generation and $49 \%$ of the overall installed capacity in 2020 [2]. Much (48.4\%) of China's total coal consumption was fed into coal-fired power plants in 2018 [3]. Meanwhile, coal consumption has caused severe environmental problems and abundant carbon dioxide emissions. Based on this, China's coal-based power production structure has brought about increasingly prominent environmental problems, which have not only caused a large amount of carbon dioxide emissions but also brought about negative environmental impacts, such as smoke, sulfur dioxide, acid rain, and smog, in different periods. According to the "Annual Report of Environmental Statistics in 2019" published by the Ministry of Environmental Protection, the power and heat production and supply industry is the second-largest contributor to the emission of air pollutants. The emission of nitrogen oxides is 1.287 million tons, accounting for $23.5 \%$ of the national industrial nitrogen oxide emissions. The sulfur dioxide emissions were 941,000 tons, accounting for $23.8 \%$ of the national industrial sulfur dioxide emissions. The particulate emissions were 565,000 tons, 
accounting for $6.1 \%$ of the national industrial emissions. According to the data of the National Bureau of Statistics, China's total coal consumption from 2016 to 2018 was 388,820, 391,403 , and 397,452 million tons, respectively, showing an increasing trend. In the future, the large-scale consumption of coal will not only cause an overload of the atmospheric environmental capacity but also cause serious climate change problems. In today's China with frequent environmental problems, the developmental prospect of coal-fired power generation is particularly concerning, and the development of clean coal-fired power is imminent and has even become a major issue of energy development. Given its remarkable role in coal utilization and electricity supply, the Chinese government is dedicated to exploring a green sustainable path for the coal power industry.

Since the 1980s, the Chinese government has heavily funded the research, development, and commercialization of clean, high-efficient, coal-fired power technology. Along with supportive industrial policies and fiscal incentives, the advanced clean coal power technologies, such as ultra-super-critical coal-fired power technology, super-critical CFB technology, ultra-low-emission control technology, etc., have been well-developed and entered the industrial application phase, upgrading the national power generation portfolio $[4,5]$.

Moreover, a series of industrial standards and regulations for coal-fired power plants has been put in place to improve the operating performance in terms of efficiency enhancement and emission reduction. For the long term, the coal-fired power industry has been one of the major contributors to air pollution in China; however, the absolute emissions have been cut down due to increasingly stricter environmental regulations. Additionally, the average coal consumption rate per $\mathrm{kWh}$ has been continuously upgraded through energy-saving retrofit and lean operation management.

However, the entire coal power industry has been struck since 2015 by a confluence of slowing power demand growth, rapid renewable increase, and squeezed profitable margins caused by rising coal prices [6] and declining tariffs [7]. To effectively solve this dilemma, the government has released corresponding countermeasures, including launching the alarming index system, opening auxiliary service market, and so forth, to guide capacity deployment and reposition coal-fired power as an adjusting power source.

According to the environmental Kuznets curve theory, the process of economic growth will eventually limit the environmental degradation caused by the early stages of development [8]. The awareness of climate change risks and the importance of environmental regulations in developing countries is also steadily increasing [9]. As an emerging country in the advanced stage of development, China went through a period when the significance of environmental protection was not well-recognized. At present, the Chinese government pays serious attention to environmental pollution and climate change and actively promotes the work of carbon emission reduction. The strategic goal of emission peak by 2030 and carbon neutrality by 2060 was formally set in 2020. For the problem of carbon peak, according to the changes of carbon dioxide emissions and economic growth, scholars drew the conclusion of decoupling in the near future. When carbon emissions are strongly decoupled or weakly decoupled, the future carbon emissions may be in a state of peak sooner or later. This result fits well with the theory of environmental Kuznets curve. In 2011, as one of the innovative measures of China's carbon emission reduction policy, carbon market trading was gradually launched in eight pilot provinces and cities in China (Beijing, Shanghai, Guangdong, Tianjin, Shenzhen, Hubei, Chongqing, and Fujian). The study showed that the Kuznets curve between capita GDP and carbon emissions was more pronounced after the introduction of the carbon trading pilot. The relationship between China's coal-relevant pollution and per capita income from 2004 to 2019 can be described with the environmental Kuznets curve.

\section{(1) Descriptions about environmental Kuznets curves}

As shown in Figure 1, as large shares of $\mathrm{SO}_{2}, \mathrm{NOx}$, and dust emissions are caused by coal combustion in China, we illustrate the three emission curves from 2004 to 2019. It is obvious that the three pollutant emissions followed the environmental Kuznets hypothesis 
during the period, indicating a remarkable pollution control progress of the coal-relevant industry in China.

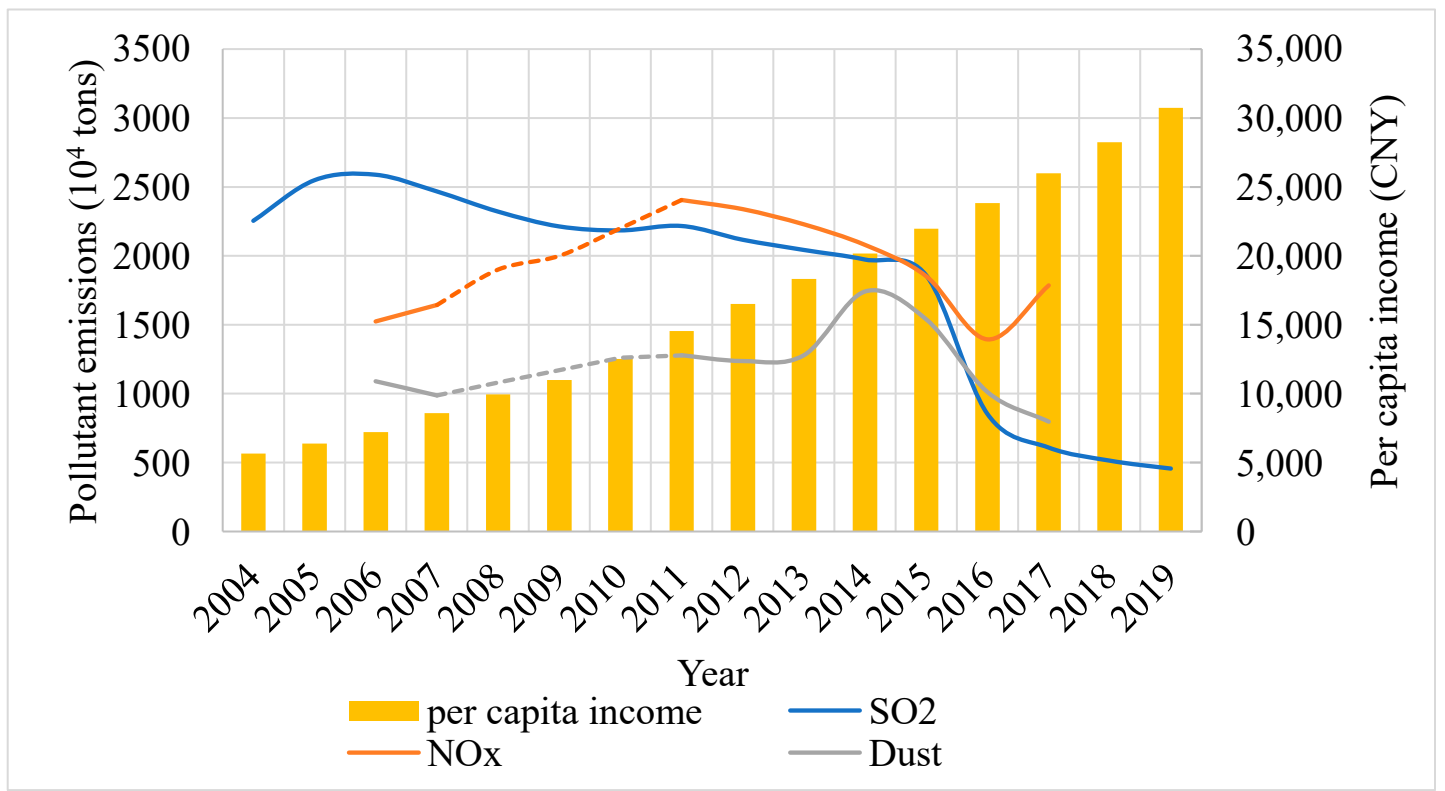

Figure 1. The coal-relevant pollution and per capita income of China (2004-2019).

(2) Description of China's carbon emission trading system

Since 2013, various pilot carbon markets have started to operate one after another. Although China has a small number of pilots in the pilot phase, the carbon emissions covered are only smaller than the EU's carbon trading system. For each pilot market, the local competent authority formulates rules based on the local conditions. Adopting a high degree of local autonomy can not only mobilize local enthusiasm for participating in the carbon market but also make the carbon market flourish, providing a multilevel reference and rich experience for the establishment of a unified national carbon market.

Compared with the international carbon market, China's pilot carbon prices are generally low. The historical highest point of carbon price in China's pilot projects was 122.97 CNY/ton (Shenzhen), and the lowest point was $1 \mathrm{CNY/ton} \mathrm{(Chongqing);} \mathrm{while}$ the European Union's EUA carbon quota spot carbon price was $€ 47.91 /$ ton (equivalent to approximately $380 \mathrm{CNY} /$ ton). The lowest point was $€ 2.68 /$ ton (equivalent to approximately $22 \mathrm{CNY} /$ ton). From the perspective of the overall carbon price change trend, the average carbon price of the domestic carbon pilots showed a downward trend from 2013 to 2017 and then rebounded in 2020. Except for Shenzhen and Fujian, the average annual carbon prices of the other carbon pilots also showed this feature. At the same time, starting from 2021, the carbon prices of the pilots have a trend of convergence. If we exclude the Shenzhen and Fujian carbon markets, where the carbon prices are less than $10 \mathrm{CNY} /$ ton, the carbon price basically fluctuated between 20 and $50 \mathrm{CNY} /$ ton in the past 3 months. From the perspective of the carbon trading volume, Guangdong, Hubei, and Shenzhen are at the forefront of the carbon pilot projects. By the end of 2020, the total trading volume was $151 \mathrm{Mt} \mathrm{CO}_{2}$, $72 \mathrm{Mt} \mathrm{CO}_{2}$, and $45 \mathrm{Mt} \mathrm{CO}_{2}$, respectively. However, from the perspective of the carbon pilot activity (the ratio of the total trading volume to the total carbon pilot allowances), the activity of the Shenzhen carbon pilot was the highest, reaching $14 \%$, which means that there were some of the carbon allowances initially allocated by the Shenzhen carbon market in 2015. About $14 \%$ of the volume was circulated in the market, while other carbon markets were active at $10 \%$ or less. From the perspective of the carbon trading volume, the total trading volume of the carbon pilots decreased in 2020, but the total trading volume increased, and there was a disagreement for the first time. In 2020, except for the increase in the carbon trading volumes of Hubei and Tianjin, the other carbon pilots were affected 
by the epidemic. With similar trading volumes, the carbon trading volumes of Guangdong, Hubei, and Shenzhen also ranked in the forefront. Among them, the carbon trading volume of Guangdong was much higher than that of the other carbon pilots. In terms of carbon emissions from the coal power industry, the authors used LMDI decomposition model to analyze the factors of the carbon emissions from coal power industry in China and found that the energy structure, economic scale, and population scale have a positive driving effect on carbon emissions from the coal power industry. The power supply structure, coal consumption, and power intensity have a negative driving effect on carbon dioxide emissions from the coal power industry. With the improvement of the energy utilization rate and thermal power generation technology in China, the power intensity and coal consumption have become the main factors that restrain the carbon emissions of the power industry [10]. In another study, the author conducted a spatial high-resolution analysis to estimate the life cycle carbon emissions of the coal-fired power industry. The results showed that, from 2016 to 2020, thanks to the optimization of the technological structure and energy savings and emission reductions, the carbon emission factor of most provinces dropped by $3-6 \%$. The reduction of the carbon emission factor resulted in a total carbon



In terms of pollutant control in the coal power industry, China has carried out a lot of work and made huge contributions. In recent years, China has promulgated the relevant laws and regulations, such as the "Coal Power Energy Conservation and Emission Reduction Upgrading and Retrofit Action Plan (2014-2020)". Pollutant emission standards have become stricter and lower, with lower emission performances. From 1979 to 2016, the thermal power generation increased by 17.5 times, the soot emissions fell $94 \%$ from the peak of 6 million tons, the $\mathrm{SO}_{2}$ emissions fell $87 \%$ from their peak, and NOx emissions fell $85 \%$ from their peak. Air pollutants from coal-fired power plants are no longer the main factor affecting environmental quality [12].

The first and foremost step to developing an effective policy and plan for carbon reduction is to establish an accurate carbon emission inventory of the Chinese coal-fired power industry.

In recent years, China has promulgated many policies related to the coal power industry. In the process of actually promoting the cleanliness of coal-fired power plants, the government has introduced many plans, such as the "Air Pollution Prevention and Control Action Plan", "Coal Power Energy Conservation and Emission Reduction Upgrade and Retrofit Action Plan (2014-2020)", "Comprehensive implementation of ultra-low-emission and energy-saving transformation work plan for coal-fired power plants", "Three-Year Action Plan to Win the Blue Sky Defense War", etc. These plans are the policy documents that have the greatest impact on the clean development of the coal-fired power industry, which directly speed up the progress of the environmental protection transformation of coal-fired power plants.

In December 2015, the former Ministry of Environmental Protection, National Development and Reform Commission, and National Energy Administration jointly issued the "Comprehensive Implementation of Ultra-low Emissions and Energy-saving Reformation Work Plan for Coal-fired Power Plants", which pointed out that the full implementation of ultra-low-emission and energy-saving transformation of coal-fired power plants is an important national special action, which is conducive to promoting the transformation and upgrading of the coal power industry. In terms of environmental constraints, China has formulated the "Emission Standards for Air Pollutants from Thermal Power Plants". This standard is one of the most important regulatory constraints that directly affect the clean-up process of coal-fired power plants, as well as a programmatic document for the emission reduction of pollutants from coal-fired power plants. In terms of incentive policies for cleaning coal-fired power plants, "Environmental Protection Law of the People's Republic of China" and "Air Pollution Prevention Law of the People's Republic of China" point out from the legal level that "the people's government shall adopt fiscal, tax, price, government procurement and other policies and measures to encourage and support them". 
On 22 April 2021, President Xi Jinping proposed at the "Leaders' Climate Summit" that China will strictly control coal power projects, strictly control the growth of coal consumption during the "14th Five-Year Plan" period, and gradually decrease during the "15th Five-Year Plan" period.

The development of China's coal industry, in accordance with the improvement of power generation efficiency, will control the emission of air pollutants and then reduce carbon dioxide emissions in the direction of continuous progress [13]. In the future, China's energy structure will be transformed, facing the challenge of a large accumulation of highcarbon energy assets and difficulties in transformation. The coal-fired power generation industry must actively transform, deploy early, and transform into a low-carbon and green development model as soon as possible. The coal-fired power generation industry should improve the efficiency of coal-fired power generation units and complement the advantages of clean energy, replacing small- and medium-sized coal-fired generating units with large coal-fired generating units with high efficiency and ultra-low carbon emissions with high parameters while researching and developing energy-saving and low-carbon technologies suitable for coal-fired generating units, and actively achieve "ultra-low-carbon" emissions [14].

In summary, with the world's largest coal-fired power generation capacity, coal power plays an important role in the country's energy system. Meanwhile, in the ongoing "14th Five-Year Plan", there are different opinions on the development trend of China's coal power industry both officially and in the industry. It is also unclear about the policies of the coal power industry from the central and local governments. Therefore, it is necessary to conduct a retrospective study on the policy effects on China's coal power industry and give a prospective analysis for the future.

This paper focuses on how and to what extent the relevant policy has driven and will continue to promote the sustainable development and commercial application of coalfired power in China. Based on a historical data analysis and qualitative discussion, we give targeted prospects for policy-makers about how China's coal power industry should develop in the mid- and long-term future. The structure of this article is arranged as follows: Section 2 briefly reviews recent studies on China's energy policies, especially coal power-related policies. Section 3 systematically summarizes and classifies the macro-policy framework driving coal power in China. Section 4 studies the corresponding effects on the entire coal power industry. Section 5 concludes with the policy implications.

\section{Literature Review}

As an energy consumption giant around the world, China's energy policy has been a hot topic in recent years. There were a series of studies focused on China's policy effectiveness on macro-energy development. Si [15] examined the effects of energy-related policies in China on energy consumption and concluded that certain types of policies like subsidies and nonmonetary awards are effective, while some exert even perverse consequences. $\mathrm{Li}$ [16] reviewed China's policy achievements and challenges related to energy efficiency and emissions during the 11th and 12th Five-Year Plans. Khanna [17] quantified the energy and emissions reduction potentials of four current policies, including mandatory renewable targets, green dispatch, carbon capture development, and coal-fired generation efficiency improvement. Cui [18] explored policy implications from both macroand micro-perspectives for mitigating carbon emissions from the power industry in China.

Given its undeniable importance in China, many studies have focused on the projection and prospective of coal power in the mid and long term under various policy scenarios. Jakob et al. [19] studied the future development trend of coal in a carbon-constrained climate. Lin [20] found that coal power will continue to serve as one of the core drivers of coal use in China, which had not peaked and would keep growing at least until 2020. Yuan [21] studied that China's "new economic normal" had a large effect on the projection electricity demand, and coal power was expected to reach its peak in 2020, then enter a plateau. Feng [22] and Yuan [23] analyzed the potential consequences of overcapacity for 
the deregulation of power generation planning and elimination of coal power subsidy in China.

Many researchers have highlighted the economics and the implementation of clean coal power-related regulations and policies. Zhao [24] studied the economical rationality of China's 13th FYP (Five-Year Plan) capacity planning target for coal power under the present price regulations and slowing electricity growth based on the LCOE (Levelized Cost of Energy) analysis for coal power generation in China. Li [25] estimated the benefits and costs of electric power policies related to efficiency improvement and emission reduction in China's 13th FYP. Zhang [26] and Li [27] focused on environmental policy implementation, as well as the reduction potential, of conventional air pollutants when the ultra-lowemission policy is well-implemented in China. Yang [28] and $\mathrm{Wu}$ [29] researched the costeffectiveness of ultra-low-emission limit policies and suggested a more holistic pollutant control framework to better facilitate diverse technology diffusion.

Meanwhile, there is a lot of research related to the development and commercial application of clean coal power technology inside and outside of China among the key options to achieve sustainable development. Chen [5] and Chang [4] reviewed China's remarkable progress in the R\&D of clean coal technologies in past few decades. Wang [30] found that technological catch-up mainly warranted decreasing the coal intensity of electricity generation in coal-fired power plants from 2009 to 2012. Na [31] elaborated the penetration status of clean coal technology and probed its influence on China's power industry. Yoro and Sekoai [32] studied the potential of $\mathrm{CO}_{2}$ capture and storage technology in South Africa's coal-fired thermal power plants.

However, few studies have focused on how policies drive the upgrading and commercialization of specific energy technologies. Lin [33] investigated the effects of wind power-related policies, including feed-in tariffs and research and development spending, on wind power technology innovation in China. As China's key power generation technology, the interaction between clean coal technology development and specific policy drivers is short of study.

This paper reviews the macro-framework of the coal power policy in China historically from top-level planning to industry regulation, as well as its implications, and draw a dynamic and holistic perspective on the technology development and commercialization of the coal power industry.

\section{Policy Driver Analysis}

As one key growth driver, China's coal power industry has been tightly tied to the national economy, while, in different development stages, it has played corresponding roles, in turn determining coal power policies. Here, China's macro-energy policy is summarized, as well as the developing guidance of the coal power sector for the past two decades, in Figure 2. From the ninth Five-Year Plan period to today, with China's electricity market switching from a tight supply to supply-demand balance and to oversupply, the power industry places more emphasis on the quality of development and prudent regulations.

Given the combination of the recent electricity surplus, booming renewable development, tightening environmental requirements, and new round of power market reform, the coal power industry is facing complicated challenges. Figure 3 illustrates the present policy framework driving the coal-fired power development in China. While, in the past supply shortage period, coal-fired power was posed as a fundamental electricity source, the power system with increasing intermittent renewable and more volatile load demands instead require coal power to provide more peak shaving, frequency adjustment, and other auxiliary support for power systems. 


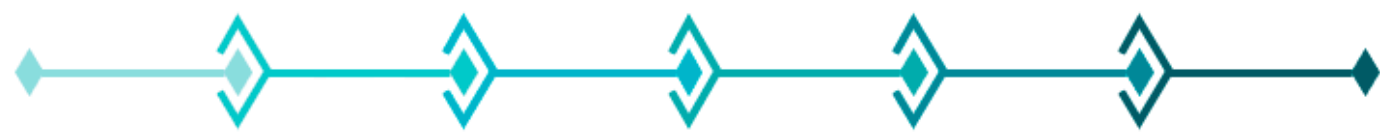

\begin{tabular}{|c|c|}
\hline \multirow{3}{*}{$\begin{array}{l}\text { Match energy with } \\
\text { economic growth } \\
\text { Continue promoting } \\
\text { power infrastructure }\end{array}$} & $\begin{array}{l}\text { Optimize structure } \\
\text { Position coal as basic }\end{array}$ \\
\hline & resource; \\
\hline & adjust \\
\hline onstruction & portfolio; \\
\hline layout; & power \\
\hline market- & reform; \\
\hline riented & renewable; \\
\hline reform. & promote \\
\hline & $\begin{array}{l}\text { saving and integrated } \\
\text { utilization. }\end{array}$ \\
\hline oal power industry & Coal power industry \\
\hline $\begin{array}{l}\text { oost pithead coal } \\
\text { ower proportion in }\end{array}$ & $\begin{array}{l}\text { Take full adv } \\
\text { of existed powe }\end{array}$ \\
\hline gions rich in coal; & positively \\
\hline capital & pithead \\
\hline duction \& energy & encourage \\
\hline ersition. & $\mathrm{CHP}$ and integrated \\
\hline
\end{tabular}

\author{
Sustainable develop Underline safe, robust, \\ Orderly develop coal; economic, clean \\ accelerate exploit oil Accelerate sustainable \\ and gas; actively development, prioritize \\ exploit hydro-power, energy conservation, \\ optimize coal power, improve efficiency, \\ and promote nuclear; control overall energy \\ vigorously develop consumption cap. \\ renewable.
}

\section{"Four Revolutions One Innovation" Attach further more importance on quality of development, structural adjustment, system optimization, market mechanism, economic competition.}

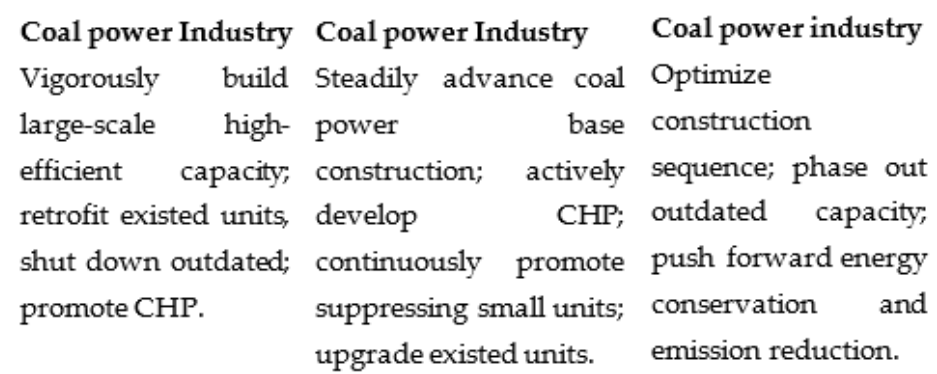

Figure 2. China's macro-energy policies and coal power guidance for the past two decades.

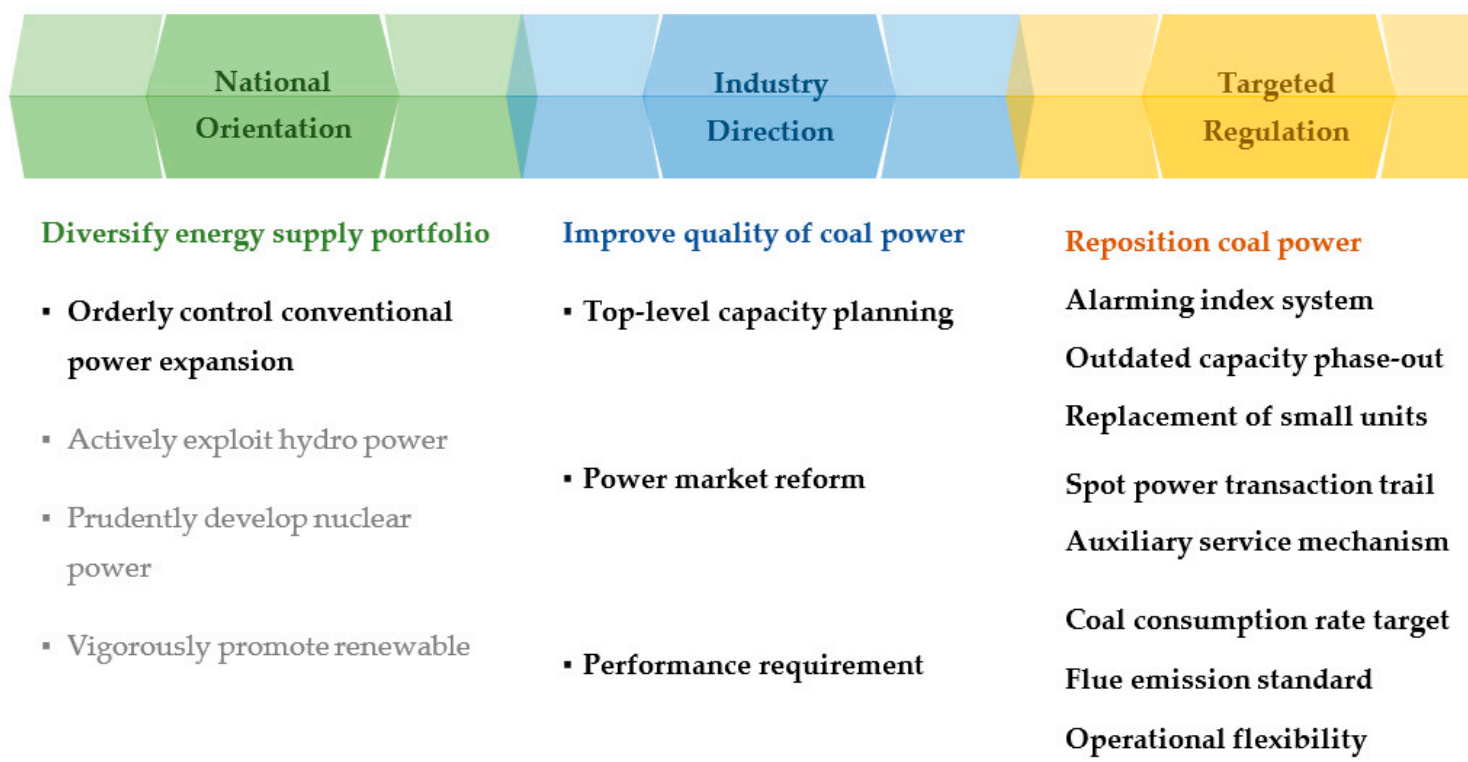

Figure 3. China's macro-energy policies and coal power guidance for the past two decades.

\subsection{Top-Level Capacity Planning}

Since the reform and opening-up policy announced in China, the power sector, especially coal-fired power generation fleet, has experienced a soaring growth to underpin the unprecedented economic booming. However, in the earlier 13th Five-Year Plan period, China encountered a turning point from high-speed to a new normal one of economic growth, thereby the increase of the electricity demand slowing down from a growth rate 
of $8.4 \%$ in $2010-2013$ to $3.6 \%$ in 2014-2016. Moreover, with the renewables taking a growing proportion in the power supply mix and a large amount of coal-fired power projects entering operation, a noticeable threat of overcapacity surged in the coal power industry. To tackle this supply-demand imbalance, the Chinese government issued a series of overall capacity-controlling measures, which aimed to limit the coal-fired power generation capacity to less than $1100 \mathrm{GW}$ and gas-fired power generation capacity to $110 \mathrm{GW}$ in 2020 [34].

The Nation Energy Administration of China, in April 2016, launched the Planning and Construction Alert Mechanism for Coal-fired Power (Coal Alert, briefly) to cancel, stop, or delay the construction of new coal-fired projects [35,36]. This Coal Alert evaluated the overcapacity degree year by year to strictly control additional units via the three dimensions of capacity adequacy, resource constraints, and new project economics; accordingly, provinces across the country were graded and classified into three categories, of which the first-class region without overcapacity had no special restrains for new projects, the second should suspend new project approval and push forward the projects under construction in an orderly fashion, and the third with significant overcapacity should not only suspend new projects but also delay the projects under construction.

The Coal Alert policy was supplemented by the measures of phasing out outdated facilities started from 2005 and building large-capacity units along with shutting down small-capacity units, targeted to optimize the existing coal-fired fleet. During the 13th Five-Year Plan period, the government plans to eliminate backwards coal-fired power units about $20 \mathrm{GW}$ [35]. Three kinds of units were put on the phase-out list, including units with small capacity and long operation times and retrofitted units with coal consumption rates still higher than the permission limit, as well as units with pollutant emissions not matching the standard released in 2011. Some provinces offered incentives like dispatch priority to encourage large-scale high-efficient coal power projects.

\subsection{Operational Performance Requirement}

With the electricity shortage easing, the Chinese government has placed more emphasis on the operational quality of the existing coal-fired power plants rather than seeking rapid capacity additions to close electricity supply gaps. The Nation Development and Reform Commission (NDRC, briefly) of China announced a series of measures to upgrade and transform the existing coal-fired power facilities to improve the energy efficiency and reduce emissions.

With the coal-fired power technology advancing continuously for decades, stricter regulatory requirements on energy efficiency have been applied for both existing units and new facilities. As for new projects, the threshold of approval has been raised, and the average coal consumption rate must be lower than $300 \mathrm{gce} / \mathrm{kWh}$; as for existing units, the average coal consumption rate should not exceed $310 \mathrm{gce} / \mathrm{kWh}$ through technical retrofit by 2020 [37]. To motivate energy conservation in coal power plants, the plants with lower coal consumption rates could get higher priority under the energy-saving dispatch mechanism.

From the 1991 version to the latest 2011 version [38,39], China's emission standards of air pollutants for thermal power plants have been tightened to the lowest level worldwide, with no more than $30 \mathrm{mg} / \mathrm{m}^{3}$ of dust, $100 \mathrm{mg} / \mathrm{m}^{3}$ of $\mathrm{SO}_{2}, 100 \mathrm{mg} / \mathrm{m}^{3}$ of $\mathrm{NOx}$, and $0.03 \mathrm{mg} / \mathrm{m}^{3}$ of $\mathrm{Hg}$, which is firstly listed out as a mandatory emission limit. In the east coast region with a tight environmental capacity, in 2014, the Action Plan declared even stricter requirements, with no more than $10 \mathrm{mg} / \mathrm{m}^{3}$ of dust, $35 \mathrm{mg} / \mathrm{m}^{3}$ of $\mathrm{SO}_{2}$, and $50 \mathrm{mg} / \mathrm{m}^{3}$ of NOx, known as ultra-low emission. The government brought incentive mechanisms such as feed-in tariffs and favorable dispatching to lead power enterprise control emissions. From July 2007, the coal-fired power units equipped with desulfurization devices could obtain a feed-in tariff [40]; from 2013, the units with dust collection and denitration systems could get subsidized. In addition, the units achieving the designated emission limits could gain an edge in the electricity market from the green dispatch scheme. 
Besides functioning as a base load power source, the coal-fired power plants in some regions bear a demanding assignment of peak shaving given the shortage of the peak load source, more intermittent renewable power, and more volatile load demand. In 2016, the government announced a clear objective to push forward the operational flexibility retrofit of 220 GW coal-fired power units. Thereof, 133 GW are located in Northeast, North, and Northwest China, consisting of a relatively higher proportion of CHP (Combined Heat and Power) units with weaker peak regulation capabilities in the heating seasons. The provincial governments of the Three Norths released a price incentive mechanism for units that can meet grid dispatching needs when experiencing a valley load and a financial penalty for those that cannot lower their output more than $50 \%$.

\subsection{Market-Oriented Reform}

During the past decades, China's power transaction mode has been launched and is transforming towards the market-oriented trading method, as well as the pricing mechanism, to rationalize the cost of power generation.

Before 2001, the coal-fired power plants had a specific electricity price allowed by the authority one-by-one when the project was approved, which reflected the needs of the return of capital and interest for the investors. Then, the operating price was introduced aiming to control the electricity at a reasonable and lower level [41]. In 2004, the benchmark price mechanism announced by the NDRC presented the average cost of coal-fired power generation by regions and initially achieved a transition from planned pricing to market pricing, facilitating social resource optimization and capital mobility [42]. Since 2015, the government has pushed forward a new round of power market reform systematically to deepen the marketization progress. The electricity participating in the trading market or spot market will be priced ultimately by competitive bidding transactions, while the rest will be traded through the benchmark mechanism.

Until the latest power market reform, the electricity generated from coal-fired units except captive ones was purchased and marketed in a unified way at the designated price and electric generation assigned by authorities. With this round of reform progressing, an increasing proportion of the electricity deal began to close via a bidding mechanism [43] rather than the previous annual electricity generation schedule.

Besides functioning as the power supply, the coal-fired power can provide a series of auxiliary services, including peak shaving, frequency regulation, backup, black-start, etc. The power generators with the required capabilities can get paid in the spot market or through the auxiliary service mechanism.

\section{Policy Effect Discussion}

\subsection{Diversify the Power Portfolio}

Coal-fired power dominated the national electricity supply mix for decades, supplemented by hydropower, given a rich-in-coal resource endowment, technological maturity, and cost advantage. In 2006, coal-fired power accounted for $80 \%$ of the total electric generation, hydropower for $15 \%$, oil for $1 \%$, gas for $1 \%$, and nuclear for $2 \%$ [44].

Since the 11th Five-Year Plan, renewable power has been experiencing a soaring growth, which can be contributed to the national political support in the form of fiscal and tax incentives and the mandatory renewable portfolio mechanism. Nuclear power construction has been positively advanced; moreover, hydropower has been exploited orderly and reasonably on the premise of ecological conservation. However, to underpin the high-speed and steady economic growth since 2000, the coal-fired power addition has surged, while its share of the installed capacity peaked around 2010.

Since renewable energy has been a growing contribution in the electricity supply mix, the diversification of China's generation fleets is deepening further, as shown in Figure 4. In 2020, coal-fired power made up $49 \%$ of the overall installed capacity, down from $65 \%$ in 2006 , while hydropower took up a slight lower share of $18 \%$, wind power accounted for $10.7 \%$, and solar for $10.2 \%$ [2]. 


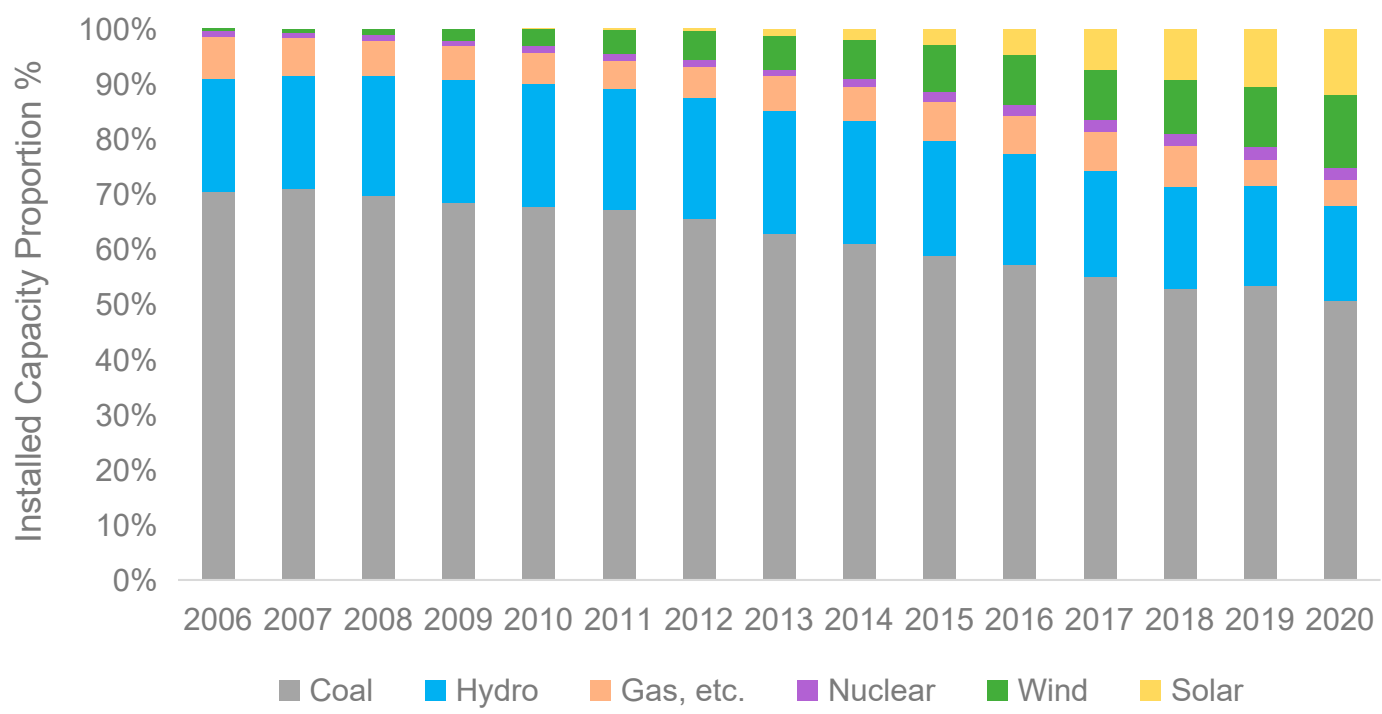

Figure 4. Installed capacity structure by power generation technologies.

\subsection{Optimizing the Coal-Fired Power Fleet}

To tackle environmental concerns, China has been accelerating the development and commercialization of clean, high-efficient coal power technology. For decades, the Chinese government has deployed a series of scientific research funds and political incentives to support and guide the transformation and upgrading of the coal-fired power industry. From the perspectives of per unit capacity and technical parameters, the coal-fired power generation fleet has been continuously optimized. Figure 5 Illustrates the transformation of the technological structure in 2005 and 2018 (300 MW represents the $300 \mathrm{MW}$-level unit, $600 \mathrm{MW}$ represents the $600 \mathrm{MW}$-level unit, and $1000 \mathrm{MW}$ represents the $1000 \mathrm{MW}$-level unit).

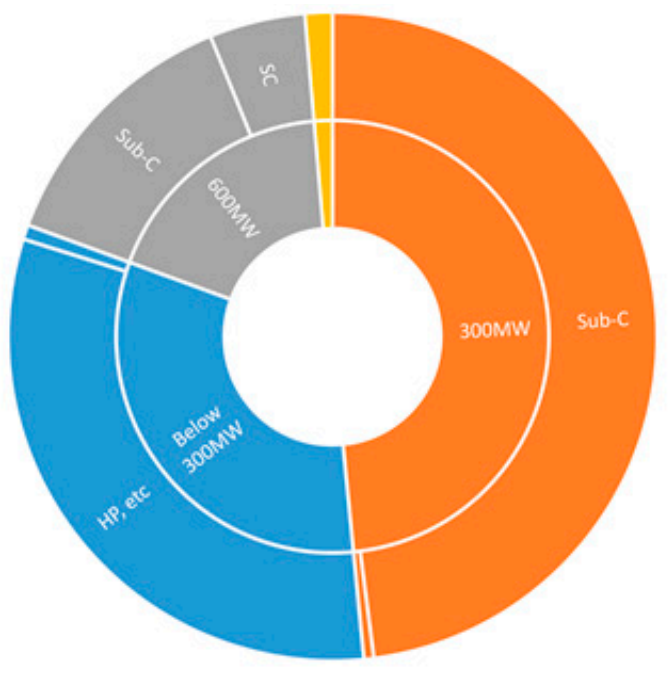

a Below 300MW $=300 \mathrm{MW}=600 \mathrm{MW}=1000 \mathrm{MW}$

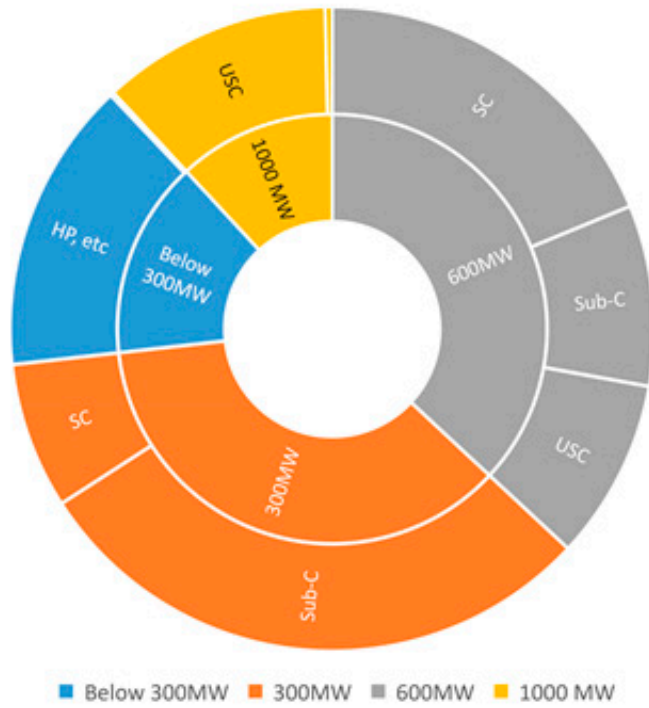

(2018)

(2005)

Figure 5. Structure of the coal-fired power capacity in 2005 and 2018.

Since the 12th Five-Year Plan, the newly installed capacity of coal-fired power was dominated by large-scale units with higher main steam parameters, as shown in Figures 6 and 7. Since 2006, more than half of the newly installed capacity were large-scale units of the $600 \mathrm{MW}$ class or $1000 \mathrm{MW}$ class, while the increase of the $300 \mathrm{MW}$ class or below were the 
units of cogeneration of heating and power. Compared with the annual capacity additions before 2005, an increasing proportion has adopted super-critical or ultra-super-critical power generation technologies since 2006 due to the stricter national technical threshold, while most of the subcritical units were cogeneration for heating and power of the 300 MW class.



Figure 6. Increased coal-fired power capacity by the unit capacity (2018).

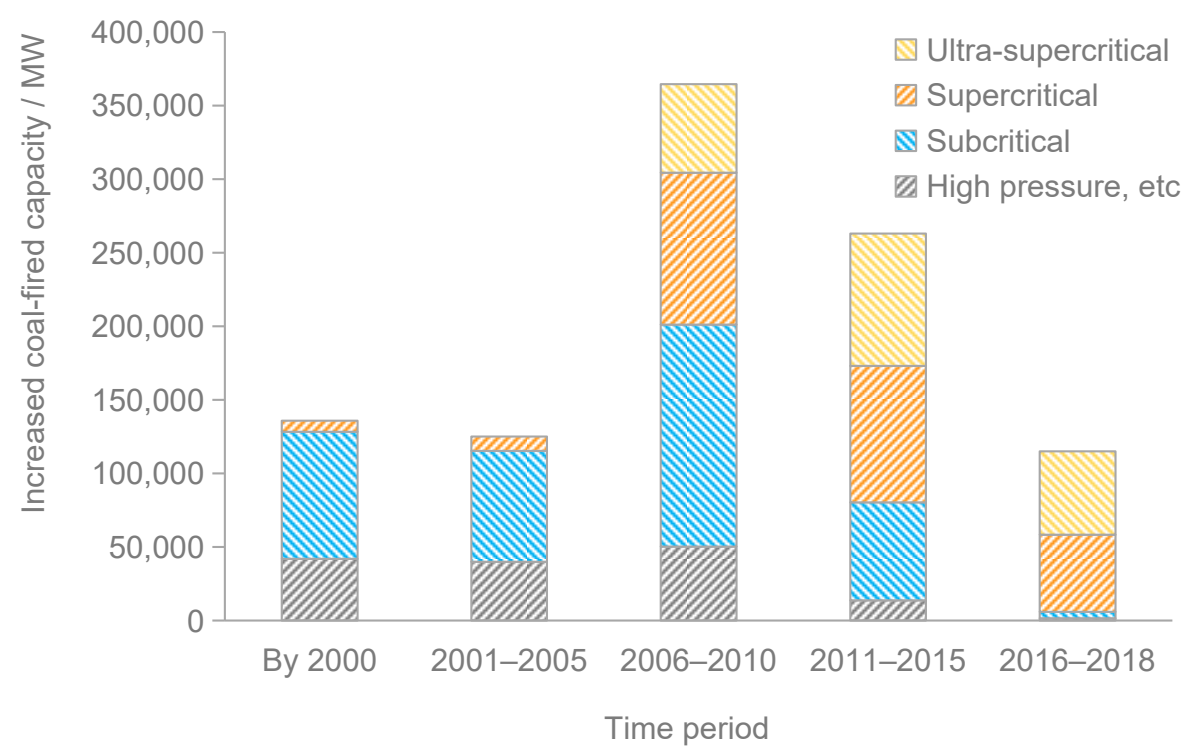

Figure 7. Increased coal-fired power capacity by the main steam parameters (2018).

As the coal-fired power development has been progressing further, the overall operational performance is being improved stably in terms of the power generation efficiency and air pollutant emissions. Figure 8 shows that the coal consumption rate of coal power generation declined around 16\% from 367 gce/kWh in 2006 to 305.5 gce/kWh in 2020 [45]. This result will be helping the technological advancement and national energy conservation policy. 


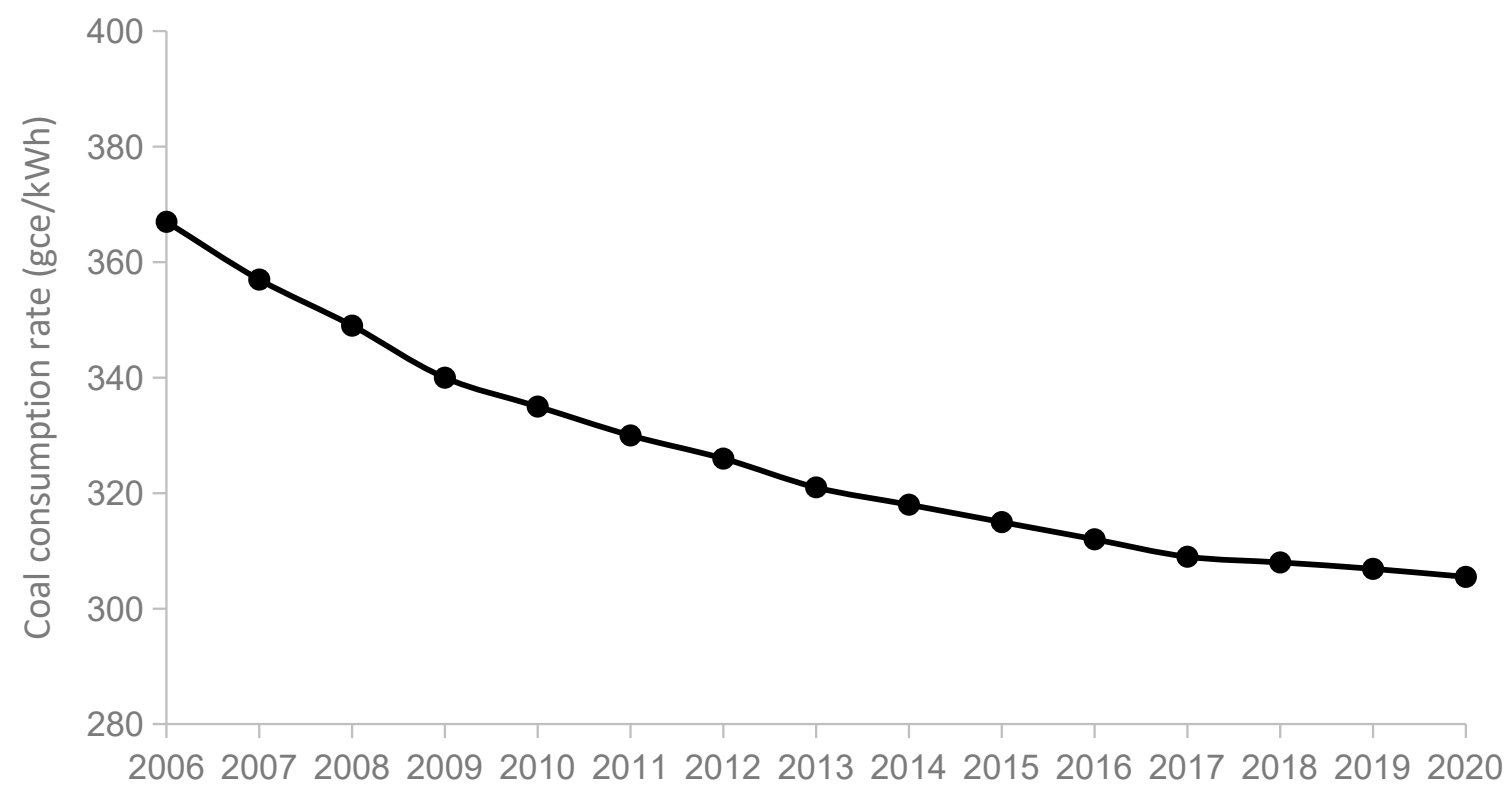

Figure 8. Average coal consumption rate of coal-fired power generation units.

With the emission standard updated even stringently to control carbon dioxide within the prescribed limit, the existing coal-fired power units should be technically retrofitted. By the end of 2018, there were more than $80 \%$ of the coal-fired power units meeting the national ultra-low-emission standards. The dust emission per unit $\mathrm{kWh}$ was $0.06 \mathrm{~g} / \mathrm{kWh}$ in 2017, cutting down from $0.39 \mathrm{~g} / \mathrm{kWh}$ in 2012, while the $\mathrm{SO}_{2}$ emission per unit $\mathrm{kWh}$ was $0.26 \mathrm{~g} / \mathrm{kWh}$ in 2017 down from $2.26 \mathrm{~g} / \mathrm{kWh}$ in 2012 [46].

Multiple measures, such as eliminating the outdated coal-fired power production capacity and making stricter entry standards for new coal-fired power (energy consumption and environmental protection), etc., have been taken to adjust and optimize the structure of the installed capacity and unit performance of coal-fired power generation.

Starting from the large-scale grid connection of new energy in the 13th Five-Year Plan and the reform of the electricity market to ensure the consumption of new energy and improve the safety and stability of the power system, more than 20 places across the country have introduced power auxiliary service market mechanisms to encourage and guide coal power to improve its flexibility. It can provide auxiliary services such as peak shaving and frequency modulation and obtain appropriate benefits.

In the context of carbon neutrality, the construction of a new power system with new energy as the main body puts forward more requirements and challenges for coal power. From the main support power source to the flexible and adjustable power source, it is necessary to assume the role of guaranteeing the supply during the transition. Some local governments are considering the transformation and orderly introduction of coal-fired power generation. Tianjin proposed to shut down the units in service without dismantling them and the small units in Zhejiang to be put into service for emergency use.

Regarding the direction of coal power transformation: in the premise of ensuring energy supply, the transition to regulation and emergency backup, more electricity will be generated by new energy sources, such as wind and solar. Specific policies, measures, and plans need to be gradually clarified. For example, the "Fourteenth Five-Year Plan for Air Quality Improvement in Zhejiang Province" has been released to promote the shutdown and withdrawal of $300,000 \mathrm{~kW}$-level coal-fired generating units or to use them as emergency backup and peak shaving units. The "Carbon Peak and Carbon Neutral Plan of Tianjin's power industry" puts forward promoting the construction of emergency standby and peak shaving power supplies. In accordance with the national deployment requirements, and under the premise of ensuring the safety and stability of power and thermal power, some units of the Panshan Power Plant, Beijiang Power Plant, and Junliangcheng Power 
Plant were optimized and adjusted as emergency peak shaving power sources, and active units of the Dagang Power Plant were retired instead of dismantled as emergency backup power sources and rationally plan to build a new emergency peak shaving power supply to ease overcapacity.

From the end of 2015 to the beginning of 2016, there was an excessive capacity situation in coal power: from the demand side, the economy shifted from high-speed growth to medium-high-speed growth, and the growth rate of electricity consumption in the whole country slowed down. The coal power project approval authority was decentralized, coal power was put into production at a high density, and the installed capacity rapidly increased. Two reasons together led to a decline in coal-fired power hours. The coal power early warning policy was released in the later period, and the coal power hours began to stabilize in 2018. Since 2016, the Chinese government has been restraining coal-fired power development amid severe nationwide overcapacity. As shown in Figure 9, the utilization hour of coal-fired power units rose to $4216 \mathrm{~h}$ in 2020 from the lowest $4165 \mathrm{~h}$ in 2016, mainly being attributed to the picking-up electric demand and alleviated capacity addition.

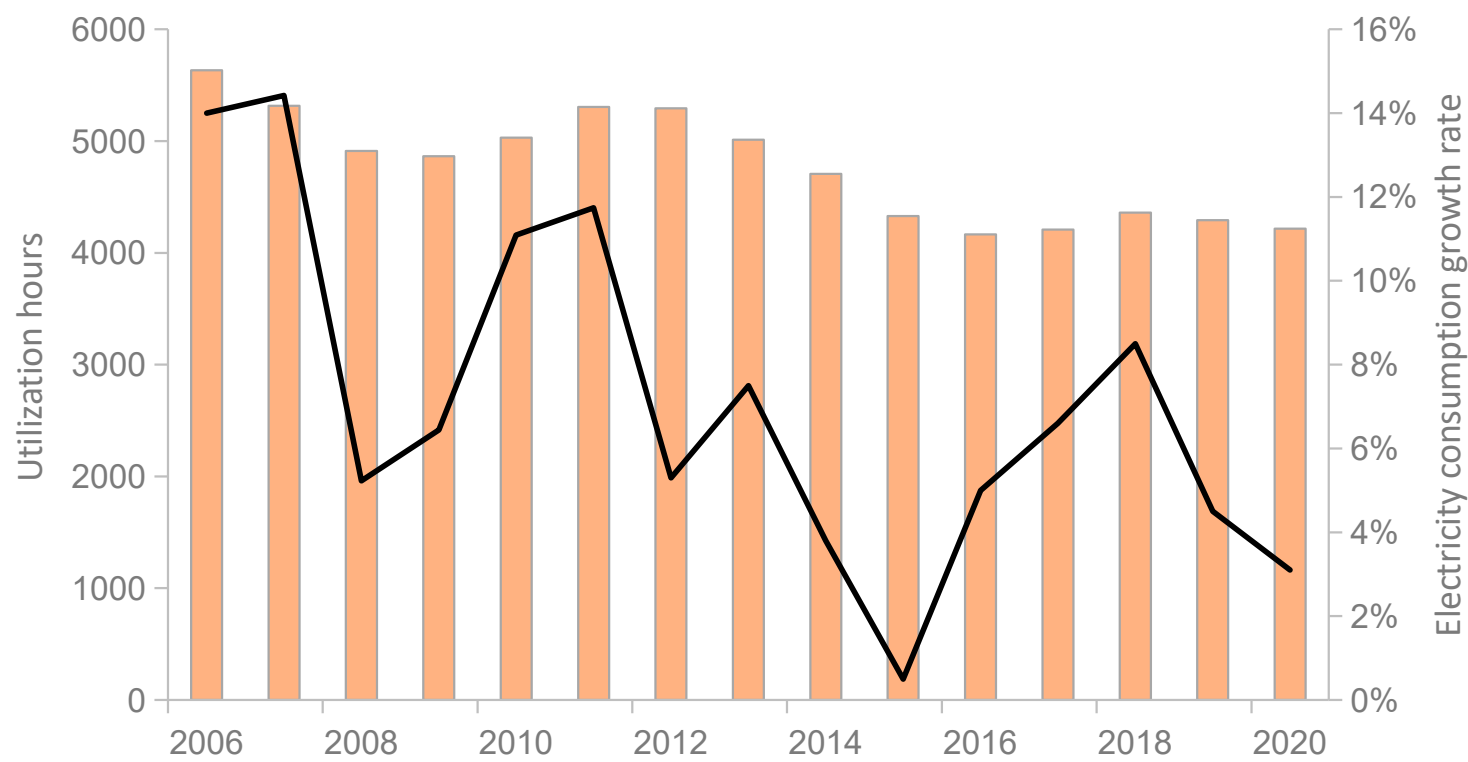

Figure 9. Annual utilization hours and electric consumption growth rate of coal power units.

The nationwide electricity consumption growth rate rebounded from the lowest level of $0.5 \%$ in 2015 to a moderate level, while the coal-fired capacity additions were cut down since 2016, when the Coal Alert was announced publicly. These two factors together played the main role in easing the coal power overcapacity problem.

Under carbon peak and carbon neutral development, we forecast the annual coal power utilization hours to clarify its functional transformation in China's power system. According to Chinese institutes' projections on electricity consumption and national power capacity addition planning, we consider the service length left of coal power units, and the quantity balance method was used to forecast the utilization hours of coal and electricity in China.

\section{(1) Electricity demand forecast}

Based on the historical data of 2020, the growth rate of electricity consumption in 2021-2025 is set at 4\%, in accordance with the forecast of domestic institutes (China Electricity Council and State Grid). Considering the change of the electricity consumption growth rate in different stages of economic and social development, the growth rate is set at $3 \%$ from 2026 to $2030,2.5 \%$ from 2031 to 2035 , and $0.8 \%$ from 2036 to 2060 . Thus, the total social electricity consumption from 2020 to 2060 is forecasted.

(2) Calculation principle of the electric quantity balance method 


$$
\mathrm{UH}=\frac{T E-\sum_{i} C_{i} H_{i}}{C_{\text {coal }}}
$$

In Equation (1), TE is the total electricity demand, $C_{i}$ is the power installed capacity of type $i$ units ( $i$ represents power supplies other than coal power), $H_{i}$ is the operation hours of type $i$ units, and $C_{\text {coal }}$ is the power installed capacity of coal-fired units.

Among them, the prediction of each type of power installed capacity refers to the research of Tsinghua University and The General Institute of Electrical Engineering. The utilization hours of hydropower and gas power are set according to the current average domestic levels. They will be increased to $2300 \mathrm{~h}$ for wind power and $1400 \mathrm{~h}$ for photovoltaic after considering the configuration of the energy storage. It is set at $7500 \mathrm{~h}$ for nuclear power, considering safety issues. Combined with the research results of authoritative institutions in China, the installed capacity of coal power will reach a peak of 1.25-1.35 billion kW in 2025 and be retired year by year thereafter. Considering the service life of domestic units, largescale decommissioning will begin after 2030, with an average annual decommissioning of 50-65 million $\mathrm{kW}$. By 2050, the remaining installed capacity of coal power will be about 400 million $\mathrm{kW}$.

The forecasted results are illustrated in Figure 10. The figure indicates that the utilization hours of coal power units will remain relatively stable before 2035 and decrease by $200 \mathrm{~h}$ compared with 2020. After 2035, with the continuous and rapid growth of the wind and solar power capacity, the role of coal power units will transit from basic load to peak load, and the operation hours will decrease rapidly.

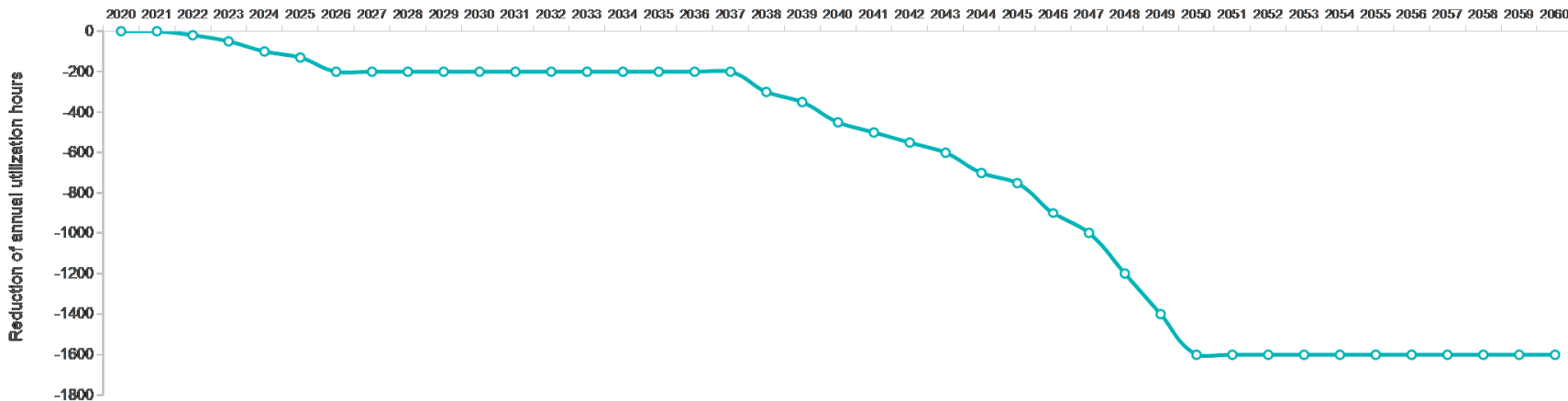

Figure 10. Forecast of the annual utilization hours reduction of coal-fired power units in China from 2020 to 2060.

\subsection{Reposition of Coal-Fired Power in the Generation Mix}

Rather than pure power supply function, China's coal-fired power industry has been transforming towards a comprehensive and multifunctional participant in the entire power system, driven by market incentives and regulation policies.

Given the increasing electricity demand from the service sector and residential usage rather than the industry and construction sectors, the peak valley difference is being intensified in power systems due to the specific load patterns in these two sectors. The economically feasible peak regulation capacity, including hydropower, pumped hydro, and gas power, is relatively scarce, especially in Northern China with lower hydropower, more CHP capacity, and more volatile renewables. Facing these challenges, coal power is designated to offer peak adjustment and frequency regulation services. To improve the operational flexibility, coal-fired power plants adopted technical retrofits, including boiler stable combustion with low loads, joint frequency control of coal power and energy storage, and heating power decoupling for heat units.

According to the statistical data from State Grid, around $40 \mathrm{GW}$ of coal power in the north region had completed technical retrofits to upgrade the operational flexibility by November 2018, achieving 30\% of the designated target in the 13th Five-Year Plan period. While before retrofitting the minimum output of generators with unit capacities larger than 
$300 \mathrm{MW}$ can be controlled down to 50\%, technical upgrading help will widen the output regulating range- that is, a minimum output of $20-35 \%$ for pure power generation units and $40-50 \%$ for CHP units. The peaking shaving service offered by coal-fired power was subsidized in the form of feed-in tariffs, 0.4-1.0 RMB/kWh in Northeast China, higher than the benchmark price.

Coal power generators equipped with batteries to provide frequency regulation are concentrated in Northern China, owing to early policy action encouraging coal power participation in ancillary services. Storage co-located with conventional power plants increased in 2018 to 65 MW. Ancillary service market trials in Shanxi and Guangdong that started in 2017 and 2018 compensated batteries co-located with coal plants for providing frequency regulation services for the grid.

\section{Conclusions}

This paper discussed the influence of policy on the development and technological progress of the coal power industry by giving an overview of the policy and reform processes of the coal power industry in China in the past 20 years. China's coal power policy has exerted a profound influence on the development of the coal power industry from the aspects of top-level design, operation regulation, and market-oriented reform. The implementation of a coal power policy, on the one hand, promotes the progress of coal power generation technology, so that the structure of coal power units tends to be dominated by large units with higher main steam parameters. On the other hand, it promotes the diversification of investment in the power industry, alleviating the overcapacity problem of coal power generation. It gradually reduces the proportion of coal power in the power supply structure and, at the same time, actively promotes the transformation of the role of coal power in the power supply and increases the flexibility and adaptability of coal power units.

During the "13th Five-Year Plan" period, China has comprehensively promoted the transformation of coal power energy conservation and emission reduction. According to the data from the Ministry of Ecology and Environment, China's coal-fired power generation units have completed the ultra-low-emission transformation of nearly 900 million kilowatts, and China's coal-fired power flue gas emission levels have reached the international best level. Meanwhile, with the global energy transition to low-carbon, China's coal power is facing multiple challenges in terms of carbon emission, environmental pollution, and high-quality economy. As the proportion of uncontrollable energy such as wind power and photovoltaic increases in the power grid, the load fluctuation on the power generation side becomes larger. On the other hand, the growth of the industrial electricity consumption slowed down, while the residential electricity consumption has maintained rapid growth. Compared with industrial power consumption, the prediction and scheduling of residential power consumption is much more difficult, and the fluctuation on the user side is larger. Therefore, in the 14th Five-Year Plan, coal power generation will be transformed from the main power source to the regulatory power source. The existing coal power generation units will possibly undertake the heavy task of peak regulation for the power system.

In the face of a future electricity system with a much higher proportion of renewable energy, coal power will still play an important role after flexible transformation. According to the discussion of this paper, we suggest to: (1) gradually reduce the average generation hours of coal-fired power units to reduce coal power generation and carbon emissions while retaining high-quality coal-fired power units within their normal life cycle as flexibility and reserve resources. (2) The other participants within the whole power system (mainly renewable energy enterprises) that adopt the support services of coal power enterprises should provide reasonable capacity compensation costs to maintain the sustainable operations of coal power units. This will create favorable conditions for China's coal power industry to achieve sustainable development and a smooth landing in the middle and long term to achieve carbon neutrality in the future. (3) It is a reasonable choice to deploy coal power units in the western and northern regions with relatively strong environmental carrying 
capacities, while conventional coal power units need to be combined with large-scale renewable energy to support the efficient utilization of renewable energy. (4) Compared with the construction of regulating the power supply, pumping storage, and energy storage, the flexibility transformation of coal power is the lowest costly way to improve the flexibility of the system. However, not all coal power units are suitable for deep peak shaving operations. For example, for number of ultra-super-critical units built in China in recent years, the output reduction operation will significantly affect their operating efficiency. Therefore, different strategies should be adopted for different coal power units, and the peak regulation potential of coal power units with low-capacity parameters should be explored.

Author Contributions: Conceptualization, J.Z. and L.P.; methodology, J.Z. and X.L.; formal analysis, J.Z. and X.L.; data curation, J.Z.; writing-original draft preparation, J.Z. and X.L.; writing-review and editing, L.P.; supervision, L.P.; project administration, L.P.; funding acquisition, L.P. All authors have read and agreed to the published version of the manuscript.

Funding: The authors gratefully acknowledge the funding from the Science and Technology Commission of Shanghai Municipality (grant no. 21692105000) and the National Natural Science Foundation of China (program no. 71704110).

Institutional Review Board Statement: Not applicable.

Informed Consent Statement: Not applicable.

Data Availability Statement: The data presented in this study are openly available on the website of the National Bureau of Statistics of China (https:/ / data.stats.gov.cn/, accessed on 1 August 2021).

Conflicts of Interest: The authors declare no conflict of interest.

\section{References}

1. Yuan, J.; Na, C.; Lei, Q.; Xiong, M.; Guo, J.; Hu, Z. Coal use for power generation in China. Resour. Conserv. Recycl. 2018, 129, 443-453. [CrossRef]

2. China Electricity Council. Compilation of Statistics on Power Industry in 2020; China Electricity Council: Bejing, China, 2021.

3. National Bureau of Statistics of China. China Statistical Yearbook 2020; China Statistics Press: Beijing, China, 2020.

4. Chang, S.; Zhuo, J.; Meng, S.; Qin, S.; Yao, Q. Clean Coal Technologies in China: Current Status and Future Perspectives. Engineering 2016, 2, 447-459. [CrossRef]

5. Chen, W.; Xu, R. Clean coal technology development in China. Energy Policy 2010, 38, 2123-2130. [CrossRef]

6. Shi, X.; Rioux, B.; Galkin, P. Unintended consequences of China's coal capacity cut policy. Energy Policy 2018, 113, 478-486. [CrossRef]

7. Yuan, J.; Li, P.; Wang, Y.; Liu, Q.; Shen, X.; Zhang, K.; Dong, L. Coal power overcapacity and investment bubble in China during 2015-2020. Energy Policy 2016, 97, 136-144. [CrossRef]

8. Kaika, D.; Zervas, E. The Environmental Kuznets Curve (EKC) theory-Part A: Concept, causes and the $\mathrm{CO}_{2}$ emissions case. Energy Policy 2013, 62, 1392-1402. [CrossRef]

9. Sadik-Zada, E.R.; Ferrari, M. Environmental Policy Stringency, Technical Progress and Pollution Haven Hypothesis. Sustainability 2020, 12, 3880. [CrossRef]

10. Zhao, Y. Carbon Dioxide Emission of Coal-Fired Power Industry Prediction Research Based on System Dynamics. Master's Thesis, Xinjiang University, Ürümqi, China, October 2009.

11. Li, J.; Wang, Y.; Xu, D.; Xie, K. High-resolution analysis of life-cycle carbon emissions from China's coal-fired power industry: A provincial perspective. Int. J. Greenh. Gas Control. 2020, 100, 103110. [CrossRef]

12. Li, B.; Wang, W.; Yao, X.; Lv, J.; Li, Z.; Ni, W. Research on the impact of coal-fired power reduction on air pollutant emission control in China. Electr. Power 2019, 52, 110-117.

13. Zhang, M. Diffusion of China's Clean Coal-fired Power Generation Technologies and Its Driving Policies. China Univ. Min. Technol. 2020, 1, 1-209.

14. Zhao, C.; Yang, J.; Wang, J.; Duan, L. Study on low-carbon development path of coal-fired power generation industry. Power Gener. Technol. 2021, 42, 548-552.

15. Si, S.; Lyu, M.; Lawell, C.-Y.C.L.; Chen, S. The effects of energy-related policies on energy consumption in China. Energy Econ. 2018, 76, 202-227. [CrossRef]

16. Li, M.; Patiño-Echeverri, D.; Zhang, J.J. Policies to promote energy efficiency and air emissions reductions in China's electric power generation sector during the 11th and 12th five-year plan periods: Achievements, remaining challenges, and opportunities. Energy Policy 2019, 125, 429-444. [CrossRef] 
17. Khanna, N.Z.; Zhou, N.; Fridley, D.; Ke, J. Quantifying the potential impacts of China's power-sector policies on coal input and $\mathrm{CO}_{2}$ emissions through 2050: A bottom-up perspective. Util. Policy 2016, 41, 128-138. [CrossRef]

18. Cui, H.; Zhao, T.; Wu, R. $\mathrm{CO}_{2}$ emissions from China's power industry: Policy implications from both macro and micro perspectives. J. Clean. Prod. 2018, 200, 746-755. [CrossRef]

19. Jakob, M.; Steckel, J.C.; Jotzo, F.; Sovacool, B.K.; Cornelsen, L.; Chandra, R.; Edenhofer, O.; Holden, C.; Löschel, A.; Nace, T.; et al. The future of coal in a car-bon-constrained climate. Nat. Clim. Change 2020, 10, 704-707. [CrossRef]

20. Lin, J.; Fridley, D.; Lu, H.; Price, L.; Zhou, N. Has coal use peaked in China: Near-term trends in China's coal consumption Energy Policy 2018, 123, 208-214. [CrossRef]

21. Yuan, J.; Lei, Q.; Xiong, M.; Guo, J.; Hu, Z. The prospective of coal power in China: Will it reach a plateau in the coming decade? Energy Policy 2016, 98, 495-504. [CrossRef]

22. Feng, Y.; Wang, S.; Sha, Y.; Ding, Q.; Yuan, J.; Guo, X. Coal power overcapacity in China: Province-Level estimates and policy implications. Resour. Conserv. Recycl. 2018, 137, 89-100. [CrossRef]

23. Yuan, J.; Guo, X.; Zhang, W.; Chen, S.; Ai, Y.; Zhao, C. Deregulation of power generation planning and elimination of coal power subsidy in China. Util. Policy 2019, 57, 1-15. [CrossRef]

24. Zhao, C.; Zhang, W.; Wang, Y.; Liu, Q.; Guo, J.; Xiong, M.; Yuan, J. The economics of coal power generation in China. Energy Policy 2017, 105, 1-9. [CrossRef]

25. Li, M.; Patiño-Echeverri, D. Estimating benefits and costs of policies proposed in the 13th FYP to improve energy efficiency and reduce air emissions of China's electric power sector. Energy Policy 2017, 111, 222-234. [CrossRef]

26. Zhang, Y.; Bo, X.; Zhao, Y.; Nielsen, C.P. Benefits of current and future policies on emissions of China's coal-fired power sector indicated by continuous emission monitoring. Environ. Pollut. 2019, 251, 415-424. [CrossRef]

27. Li, X.; Yang, X.; Wei, Q.; Zhang, B. Authoritarian environmentalism and environmental policy implementation in China. Resour. Conserv. Recycl. 2019, 145, 86-93. [CrossRef]

28. Yang, H.; Zhang, Y.; Zheng, C.; Wu, X.; Chen, L.; Fu, J.S.; Gao, X. Cost estimate of the multi-pollutant abatement in coal-fired power sector in China. Energy 2018, 161, 523-535. [CrossRef]

29. Wu, D.; Ma, X.; Zhang, S.; Ma, J. Are more economic efficient solutions ignored by current policy: Cost-benefit and NPV analysis of coal-fired power plant technology schemes in China. Ecol. Indic. 2019, 103, 105-113. [CrossRef]

30. Wang, C.; Cao, X.; Mao, J.; Qin, P. The changes in coal intensity of electricity generation in Chinese coal-fired power plants. Energy Econ. 2019, 80, 491-501. [CrossRef]

31. Na, C.; Yuan, J.; Xu, Y.; Hu, Z. Penetration of clean coal technology and its impact on China's power industry. Energy Strat. Rev. 2015, 7, 1-8. [CrossRef]

32. Yoro, K.O.; Sekoai, P.T. The Potential of $\mathrm{CO}_{2}$ Capture and Storage Technology in South Africa's Coal-Fired Thermal Power Plants. Environments 2016, 3, 24. [CrossRef]

33. Lin, B.; Chen, Y. Impacts of policies on innovation in wind power technologies in China. Appl. Energy 2019, $247,682-691$. [CrossRef]

34. National Development and Reform Commission; National Energy Administration. The Electric Power Development Planning in 13th Five-Year (2016-2020). 2016. Available online: http://www.gov.cn/xinwen/2016-12/22/content_5151549.htm (accessed on 22 December 2016).

35. National Energy Administration. Notice on Further Regulating the Planning and Construction of Coal-Fired Power Projects. 2016. Available online: http:/ /zfxxgk.nea.gov.cn/auto84/201610/t20161020_2311.htm (accessed on 10 October 2016).

36. National Energy Administration. Notice on Establishing Risk Alert Mechanism of Coal-Fired Power Planning Construction and Releasing Coal-Fired Power Alert in 2019. 2016. Available online: http://www.hebi.gov.cn/sfgw/638836/639672/639684/14460 97 /index.html (accessed on 9 May 2016).

37. National Development and Reform Commission; Ministry of Ecology and Environment; National Energy Administration Action Plan of Coal Power Upgrading and Retrofitting on Energy Conservation and Emission Reduction 2014-2020. 2014. Available online: http:/ /zfxxgk.nea.gov.cn/auto84/201409/t20140919_1840.htm (accessed on 12 September 2014).

38. Ministry of Ecology and Environment. Emission Standard of Air Pollutants for Coal-Fired Power Plants GB 13223-1991; Ministry of Ecology and Environment: Bejing, China, 1991.

39. Ministry of Ecology and Environment. Emission Standard of Air Pollutants for Thermal Power Plants GB 13223-2011; Ministry of Ecology and Environment: Bejing, China, 2011.

40. National Development and Reform Commission; Ministry of Ecology and Environment. Regulation Procedures for Environmental Protection Price Subsidy and Pollutant Control Device Operation of Coal-Fired Power Generation Units. 2014. Available online: https:/ / www.mee.gov.cn/gkml/hbb/gwy/201404/t20140404_270185.htm (accessed on 28 March 2014).

41. State Development Planning Commission (Formly). Notice on Normalizing Power Tariff Management; State Development Planning Commission (Formly): Bejing, China, 2001.

42. National Development and Reform Commission. Notice on Further Resolving Electricity Price Conflict and Normalizing Price Administration. 2004. Available online: http:/ / www.nea.gov.cn/2011-08/16/c_131052531.htm (accessed on 16 August 2011).

43. National Development and Reform Commission; National Energy Administration. Notice on Orderly Deregulating the Power Generation Quota. 2017. Available online: http://www.gov.cn/xinwen/2017-04/10/content_5184607.htm (accessed on 10 April 2017). 
44. BP Statistical Review of World Energy. 2019. Available online: https://www.bp.com/content/dam/bp/businesssites/en/global/corporate/pdfs/energy-economics/statistical-review/bp-stats-review-2019-full-report.pdf (accessed on 30 September 2019).

45. China Electricity Council. Compilation of Statistics on Power Industry in 2006; China Electricity Council: Bejing, China, 2007.

46. China Electricity Council. Research on Pollutants Emission Reduction of the Power Industry in China; China Electricity Council: Bejing, China, 2018. 